\title{
Climate change education in different countries
}

\begin{abstract}
The problem of global climate change is becoming increasingly serious every year. This phenomenon leads to irreversible destructive consequences, but, unfortunately, people are still not fully aware of this. The main objective of the study was to find out whether the younger generations have sufficient information about the problem and whether the education system requires changes. Previous studies were analysed, a survey and several interviews were conducted, the results of which confirmed the assumption about the need to inform people about this problem.
\end{abstract}

Keywords: climate change, education, awareness, educational programs

\section{Introduction}

Climate change is often used synonymously with global warming, but it is a much wider term that includes other problems that have been observed on our planet over the past several decades. The involvement of the younger generations in solving these problems is extremely important, since now we are witnessing the disappearance of the glaciers, the rise of sea levels, the disappearance of animal and plant species, and severe weather events. Most people have heard about these problems, but not everyone has information about the causes of climate change in our environment, its consequences and do not know that some factors causing these problems can be reduced even in our everyday life.

1 Student, Budapest Business University; e-mail: serendipity777@bk.ru

DOI: http://dx.doi.org/10.31570/Prosp_2021_1_5 
Raising awareness, knowledge promotion and skills development education is necessary to draw attention to the problem of climate change and to find new solutions. The UN Framework Convention on Climate Change encourages parties to promote, develop and implement educational, training, and public awareness programs on climate change and its effects. Moreover, the UN initiated a decade - UN Decade of Education for Sustainable Development 2004-2015 (ESD). Of course, education should cover a fairly wide range of areas including: legislation, policy, finance, curricula, teacher education, instruction, learning, assessment, school governance and infrastructure, teaching methods to develop critical thinking, problem solving, and forecasting events affecting both natural and human ecosystems. Education with such an approach becomes a lifelong process. In addition to ESD, another form of education, Climate Change Education, has been developed, aimed at studying the causes and consequences of climate change, as well as possible responses. This way we can get more people ready to work on climate change mitigation and adaptation in order to promote climate resilient development.

It is quite obvious that a modern person simply needs to understand this problem. Even the recent US elections tell us this, because part of Biden's presidential program was built on an environmental development plan, the intention to make serious investments in a green economy and rid the energy sector from most of emissions by 2035. That is why the purpose of this study was to find out how aware students are now of this problem, the quality of their knowledge, approach to climate change education in different countries and finally to find out how we can encourage young generations to try to find new solutions for clime change problems.

\section{Theoretical background}

\section{The problems caused by daily human activities}

According to data from Nasa Science, nowadays we can see correlations between the global warming trend and the human expansion of the "greenhouse effect" notion, warming that results when the atmosphere traps heat radiating from Earth toward space.

Gases contributing to the greenhouse effect include:

- Water vapor. The most common greenhouse gas, water vapor is the second heat source (besides sunlight) on the Earth's surface. 
- Carbon dioxide $\left(\mathrm{CO}_{2}\right)$. Since the beginning of the industrial revolution, humans have increased the concentration of $\mathrm{CO} 2$ in the atmosphere by $47 \%$, the increase in concentration is influenced by the following processes of human activities deforestation, land use, burning of fossil fuels.

- Methane. In addition to natural sources, the concentration of this gas is increased by agriculture, decomposition of waste in landfills and other human activities.

- Nitric oxide. It is formed during soil cultivation, especially commercial and organic fertilizers, fossil fuel combustion, nitric acid production and biomass combustion.

- Chlorofluorocarbons (CFCs). Synthetic compounds of completely industrial origin, emissions are currently regulated by international agreements.

In its Fifth Assessment Report, the Intergovernmental Panel on Climate Change, a group of 1,300 independent scientific experts from countries all over the world under the auspices of the United Nations, concluded there is a more than 95 percent probability that human activities over the past 50 years have warmed our planet.

The consequences of changing the natural atmospheric greenhouse are difficult to predict. On average, according to the forecasts of scientists, the Earth will become warmer, which will lead to greater evaporation and precipitation; some regions will become more humid. Rising ocean temperatures will melt glaciers and raise sea levels. Droughts, floods, and extreme temperatures can lead to loss of crops and threaten the food security of populations around the world. Finally, while increasing $\mathrm{CO}_{2}$ levels can stimulate plant growth, research has shown that it can also reduce the nutritional value of most food crops by reducing the concentration of protein and essential minerals in most plant species. Climate change has the potential to introduce new types of pests and diseases that affect plants, animals and humans and pose new risks to food security, food safety and human health.

\section{Climate change awareness and education}

The ecological crisis and the evolution of the climate in recent years have clearly indicated the need to change our thinking and attitude towards life. With this in mind, education for sustainable development is highlighted - a key factor in finding alternative ways to build a new society based on the principles of justice, citizen participation and openness to cultural diversity. According to the UNESCO, ESD is widespread in Latin America and the Caribbean. In Mexico, for example, ESD is being implemented at all 
levels of the education system, including through learning games in early childhood education, biodiversity activities and programs in primary and basic education, and the integration of environmental issues into secondary education. In countries such as Bolivia, Brazil, Guatemala, Costa Rica, Peru, Chile, and Ecuador, we are witnessing the emergence of a targeted strategy, which is reflected in specialized publications, $\mathrm{TV}$ and radio broadcasts, excursions to protected areas and training of teachers how to approach this problem.

As for the higher educational institutions of the region, according to the information collected during the implementation of the RISU project (2015) on the activities of Latin American universities in the field of ESD, 70\% of them have departments which are competent in nature protection, $86 \%$ conduct extracurricular information-educational activities on environmental protection and sustainable development, and $46 \%$ of universities conduct research in these two areas. From the materials of the same project, it follows that $46 \%$ of universities have an energy sustainability plan, and $35 \%$ are engaged in raising the awareness of the population in the field of energy conservation. Finally, 33\% of universities monitor the quality of drinking water and $61,5 \%$ have hazardous waste management departments. Half of universities have information systems for monitoring solid waste, indicating their types and quantities.

These figures are more or less encouraging. It should be noted, however, that the current focus in education is on the environmental rather than social aspects of the problem-without which efforts to achieve the Sustainable Development Goals set by 2030 by countries of the United Nations will be incomplete.

However, in 2015 a study published in Nature Climate Change concluded that approx. $40 \%$ of the world's adult population has never even heard of climate change. The study revealed a huge difference between developed and developing countries. For example, in North America, Europe and Japan, about $90 \%$ of the population is aware of the problem, while in developing countries, including Egypt, Bangladesh and India, the figure was only $35 \%$. According to this study, which analysed data in more than 100 countries, the main prerequisites for awareness are the level of education, civic engagement, and access to communication.

As for education in general, one study published by the American Geophysical Union found that the net effect of improved education was an increase in emissions in the medium term, mainly due to higher productivity, but a decrease in emissions in the long term, primarily due to slower population growth. At the same time, improved education has a positive effect on all aspects of the Human Development Index (O’Neill et al. 2020). Removing stalled gains in education and achieving goals that 
are at least in line with historical trends is particularly important for reducing future vulnerabilities.

Nevertheless, it is generally understood that awareness does not always encourage people to take responsibility or action. A few years earlier a survey about three factors - awareness, responsibility, and threat perception - showed that the United States is among the top five countries in terms of awareness, but $97 \%$ of respondents said they know about the problem of climate change, either "something" or "a lot". Research based on opinion polls conducted in 2008 and 2016 shows that 70 percent of Americans not only acknowledge that climate change is occurring, but also believe it will harm future generations. However, the main problem remains that while the United States is ahead of many countries in its awareness and concern about climate change, it is still lagging behind in recognizing human responsibility for climate change. Pelham (2009) says : "Despite the fact that the U.S. ranks third in overall awareness of global warming - $97 \%$ - only $49 \%$ of the $97 \%$ say they believe that the increase in temperature is the result of human activity. This is a very important point, because understanding the role of human beings in climate change and drawing attention to social, behavioural, ethical aspects can be a serious step towards reducing the impact of climate change through carbon reduction policies and generally more responsible behaviour.

Speaking of education, it is important to understand not only the statistics of people receiving information about the problem, but also to take into account the quality of education, the content of educational programs, and to understand the relevance of data, as research in this area constantly reveals new information.

Training programs and materials play a key role in the learning process. According to Ball and Cohen (1996), unlike standards and goals, curricula contain specific information that teachers and students process as they learn and that is part of the routine of classroom life. Studies also show that the use of higher quality textbooks is associated with higher quality learning (Sun-Kulm-Capraro 2009). As for climate change education, several researchers found that the materials used for learning about GCC do not fully address this issue. For example, a study of seven widely used Earth science and environmental textbooks found that about half of the 18 basic concepts of climate change were missing from most texts (Choi et al. 2010). In a study of over 50 Earth science texts used in England and Wales, King (2010) found images of numerous misconceptions about GCC. Analysis of course materials on geography in Ethiopia ignores potential collective mitigation efforts such as energy efficiency (Dalelo 2011). Mehan and Levy (2017) concluded in their study that many U.S. high school curricula do not have sufficient resources to prepare young people to understand and respond to climate 
change. All this leads us to the understanding that despite international programs and the work of many foundations, society still has serious problems with informing people about the problem. But the involvement of children from a young age can help in the formation of responsible, conscientious citizens, which is why it is necessary to pay attention to the need for changes in the educational program in most countries.

\section{Research questions}

The main questions of this research are:

Are students familiar not only with the phenomenon of climate change, but with its causes and prevention measures?

Is there enough information in schools and universities about the GCC problem?

\section{Research methodology}

Data for this proposed research was collected via questionnaire and interviews. The questionnaire was made on-line with Google Forms, it consists of two parts. The first one includes multiple choice questions and helps understand the general situation: countries of respondents, percentage of respondents who is familiar with the GCC problem, percentage of respondents who got information about GCC from the educational systems of their countries, etc. The second part of questionnaire includes two open questions related to solutions and practices that students suggest or that are already used by students in their everyday activities.

Interviews were conducted with students from different countries who are now studying in Hungary to summarize the questionnaire and to get a deeper understanding of people's opinions and the level of their interest in this problem.

Students were selected for participation in the research since they have relatively recently graduated from secondary school, which means they reflect a true picture of what is happening in schools and student programs. For interviews students who have experience of living in different countries were selected, in this way they can compare the situations. 


\section{INTERVIEW ANALYSIS}

5 interviews were made to understand people's opinions on a deeper level. There were 5 student interviewees from different countries, who are now studying in Budapest: Yasmin Wardeh (Jordan-USA, Óbuda University), Vasili Sagirishvili (Georgia, Budapest Business School), Elena Pshenitsyna (Russia-China, ELTE University), Shoaib Hanif (India, Budapest Business School), Ali Ahmad (Syria, ELTE University).

The first question was concerned with their knowledge of climate change, if they were familiar with problems, consequences, causes. All interviewees expressed approximately the same opinion, that they knew about this notion, but it was just basic knowledge, and it would be good to learn more about this topic. Ali and Shoaib also added that they can see consequences of GCC in their countries. They are noticeable in weather events and shifting seasons during the year. The next question was about climate change education in their native countries. Elena said that she was provided information at school but just the basics, as for university they discussed this topic during English language lectures, but only as a conversational topic. Jasmin also stated that in Jordan they have a lack of climate change education. As for Georgia, Vasili does not remember any subjects discussing that problem at school, but they had some lectures at the university. Shoaib thinks that the situation in India is becoming much better now. Although for some time the country was concentrating on development, gathering international companies and the government didn't pay attention to these problems, the situation has changed now, so they began to speak about it, discuss it, to have some summits and conferences. As for Syria Ali said, that during his educational process this topic was not covered in detail.

All participants have definitely agreed with the fact that it is a must to include a climate change program in the educational system. According to Shoaib it would be easier for children to understand what is happening in the world and to get used to useful habits from childhood. Moreover, he expressed the opinion that not only lessons and lectures are needed, but also holding meetings, conferences, attracting professors, teachers; this would help to identify leaders, and to raise the interest of the younger generations in the problem.

11 participants agreed that even the simplest actions on the part of people would help mitigate GCC, for example, avoiding overconsumption, or wise energy usage, but according to Shoaib, people are just starting to get used to taking responsibility for these actions. Elena also said that just a few years ago there was no talk about plastic recycling in her hometown, it was simply burned, like all the rest of the garbage. 
One of the questions of the interview was whether the participants knew something about the other countries' practices, perhaps they had experiences when living abroad. Yasmin lived in America for a long time and, according to her, the problem of the GCC is covered there much better, this is often discussed on TV, in the press. Elena worked in a Chinese school for several years and noted that now in China teachers are trying to tell children the basics about nature and climate from a very young age.

In general, the results of the interviews correlated with the results of the questionnaire.

\section{QUESTIONNAIRE RESEARCH ANALYSIS}

\section{Countries of respondents}

\section{Figure 1: Countries of respondents}

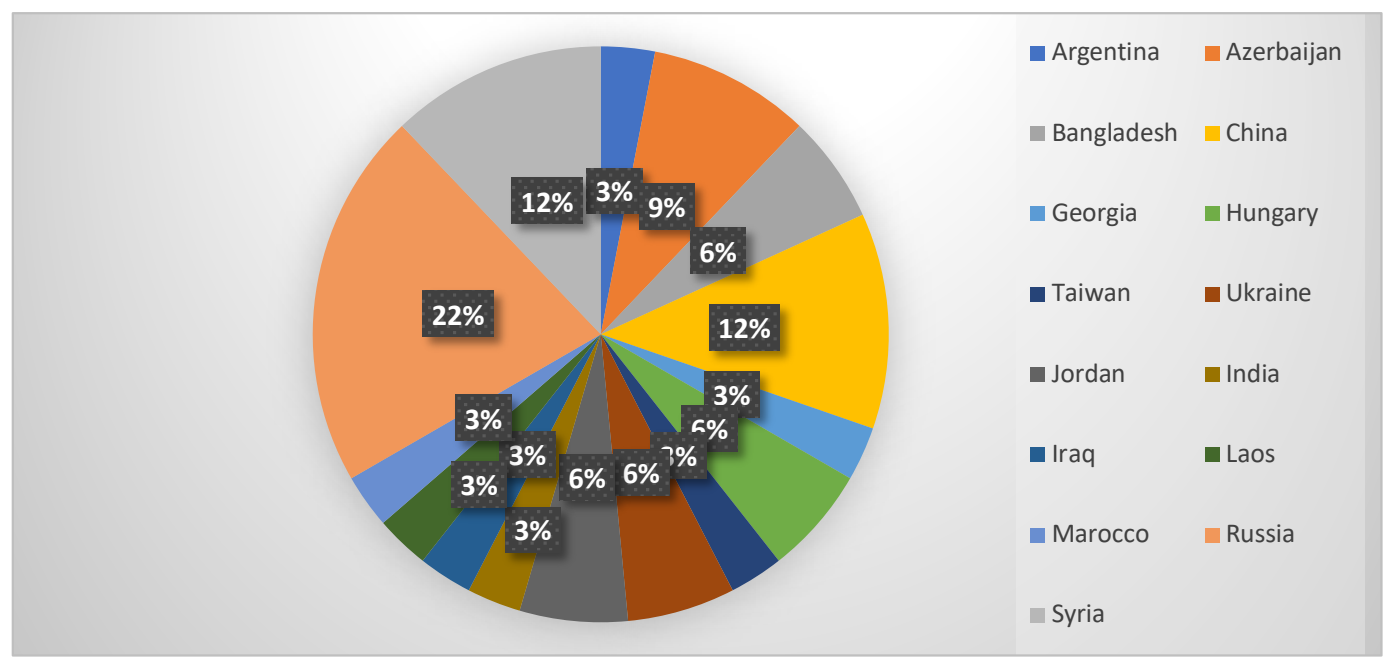

Source: own work

Students from 15 countries took part in the study. The total number of respondents was 66. Such a sample does not make it possible to understand the situation within each specific country but helps to understand the situation generally.

2. Do you think you know enough about the problem of climate change? (causes, consequences, preventive measures, etc.)? 
Figure 2: Knowledge about the problem of climate change

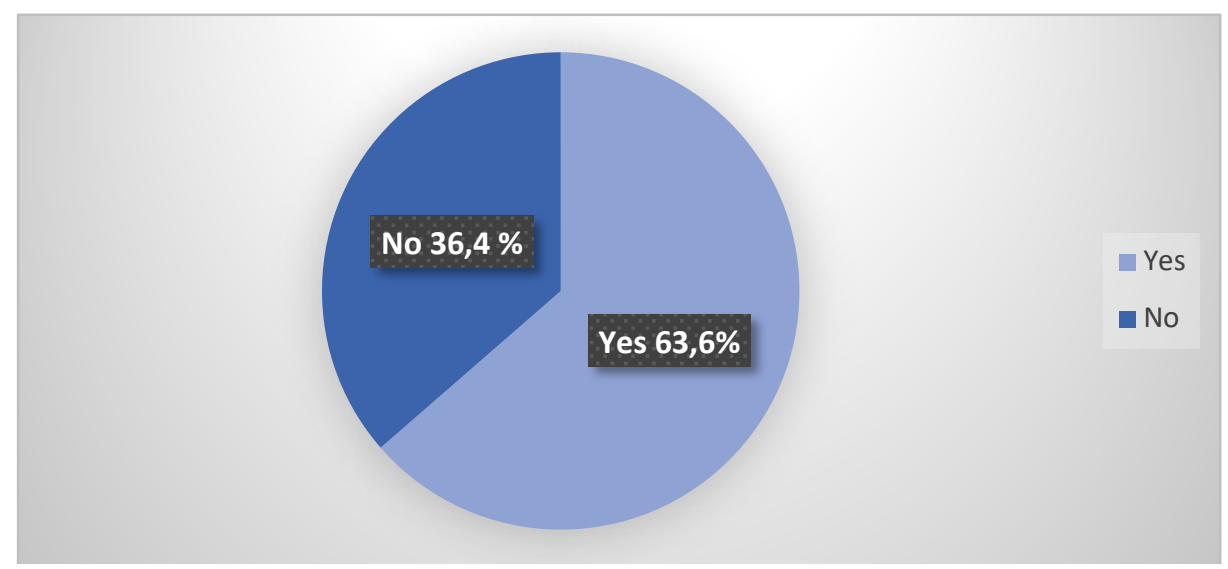

Source: own work

More than 30 percent of the respondents admitted that their knowledge of the problem is insufficient. Of course, this figure is much better than the one published in Nature Climate Change, where studies showed that about $40 \%$ of the population did not hear about the GCC problem at all, nevertheless this is a rather high figure when we talk about the younger generations.

3. Have you received any information about climate change at school or at university in your country?

Figure 3: School and university education

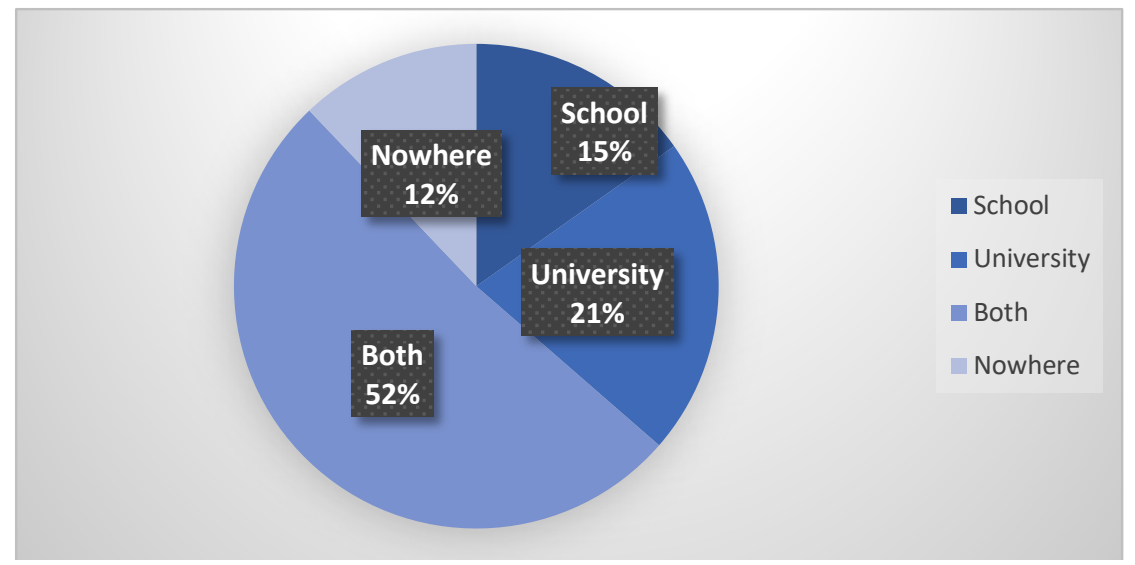

Source: own work 
The diagram shows that in more than 50 percent of the cases, respondents received information about GCC both in schools and universities, but 12\% did not receive any information on this issue during the educational process. Attention also should be paid to the fact that the number of those who received information only at university are more than those who received it only at school. School education systems need to be developed.

4. Do you know that human activities provoke most of the climate change causes?

Figure 4: Human activities

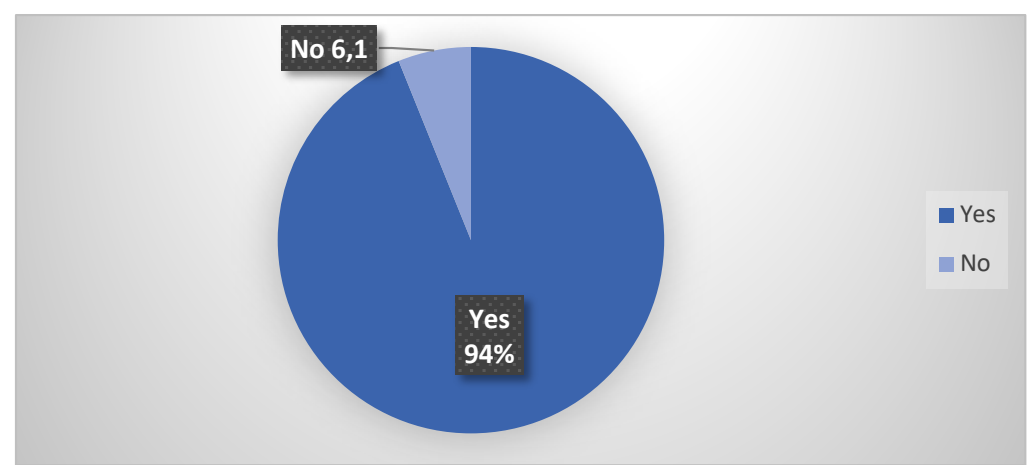

Source: own work

94 percent of respondents recognize human responsibility for the GCC problem.

5. In your opinion, adding a subject on climate change to the school and university curriculum is worthwhile? Will it contribute to dealing with this problem?

Figure 5: Educational system changes

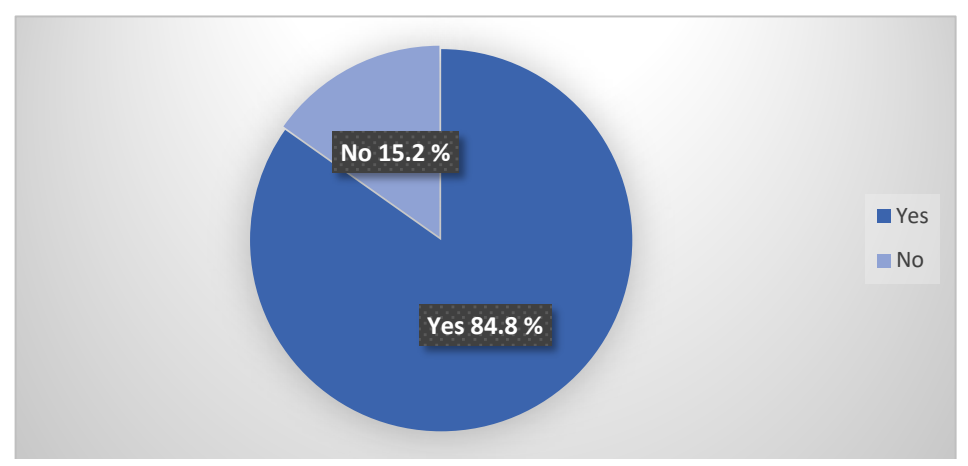


More than 15 percent of those surveyed do not think that the compulsory hours of the education program on climate change will have any positive results, but about 85 percent believe the opposite, so changes in the educational system can help us to grow up as responsible people.

\section{Do you know how your daily behaviour and habits can help reduce climate change?}

Figure 6: Knowledge about daily behaviour and habits

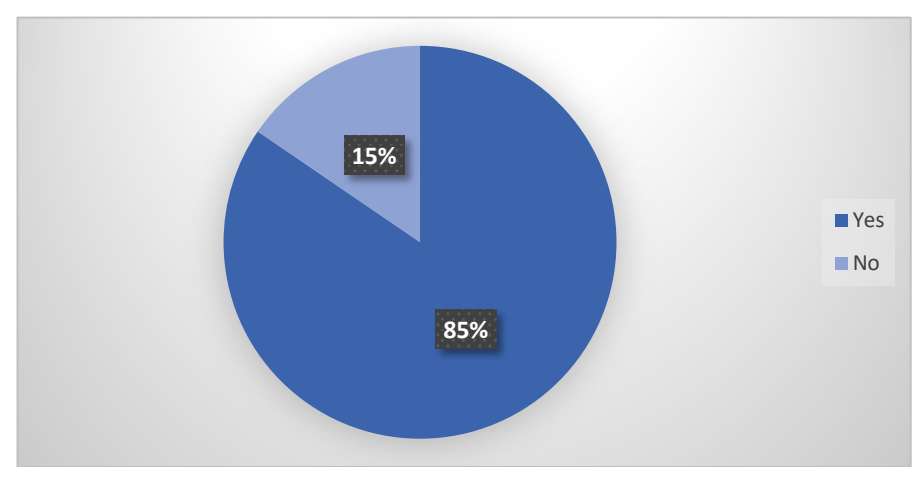

Source: own work

Since human activity is the main reason for GCC, it becomes clear that in our daily routine, we can introduce habits that will help mitigate the problem, but $15 \%$ of the respondents do not know how this can be done. It confirms the fact that we need to raise awareness.

\section{What everyday actions or habits of people in your opinion can help reduce cli- mate change?}

This question was open, with no answer options. Among the answers of the respondents, the most common advice was about water and energy consumption, reducing the use of plastic, avoiding fast fashion, public transports usage instead of car, but there were ideas about legal regulation and an interesting proposal on greening cities.

8. What practices can you suggest when dealing with climate change? May be some real-life examples were interesting for you. You can mention some interesting reallife experiences. 
Quite a few interesting practices related to material recycling and reforestation were listed, but the most interesting one was "Pleistocene park" (Sakha, Russia) - which is an attempt to recreate the ecosystem that dominated the Arctic in the late Pleistocene - the ecosystem of the Mammoth Steppes.

\section{Conclusion}

The aim of this study was to find out whether students are familiar not only with the phenomenon of climate change, but with its causes and prevention measures, too. In addition, I also wanted to find out if the provision of information about climate change at schools and universities was enough.

According to the obtained results, the problem of GCC is not very well understood by the younger generations. Despite the practices implemented by the UN and many non-profit organizations, in most countries there is a lack of education on this issue. This is evidenced by the analysis of research, scientific articles and surveys conducted in previous years.

The results of the study will help understand ways of treating the causes of climate change, that it is vital now to increase responsibility and awareness by providing a developed, modified modern form of education. Education and public awareness play an important role in building a capacity for mitigation and adaptation to climate change, enabling people to make informed decisions. Education helps students understand the causes and consequences of climate change, prepares them to live with the impacts of climate change and enables people to adopt more sustainable lifestyles. So, to encourage young generations to find new solutions for the problems of clime change in the future we have to modify educational programs, create more events which are dedicated to this topic, so this way we can raise a generation that is well oriented in the problem that they will have to solve anyway.

\section{References}

Ball, D. L. - Cohen, D. K. (1996). Reform by the book: What is - or might be - the role of curriculum materials in teacher learning and instructional reform? Educational researcher, 25(9), 6-14. https://doi.org/10.3102/0013189x025009006 
Branch, G. - Rosenau, J. -Berbeco, M. (2016). Climate education in the classroom: Cloudy with a chance of confusion. Bulletin of the Atomic Scientists, 72(2), 89-96. https://doi.org/10.1080/00963402.2016.1145906

Choi, S. - Niyogi, D. - Shepardson, D. P. - Charusombat, U. (2010). Do earth and environmental science textbooks promote middle and high school students' conceptual development about climate change? Textbooks' consideration of students' misconceptions. Bulletin of the American Meteorological Society, 91(7), 889-898. https:// doi.org/10.1175/2009bams2625.1

Dalelo, A. (2011). Global climate change in geography curricula for Ethiopian secondary and preparatory schools. International Research in Geographical and Environmental Education, 20(3), 227-246. https://doi.org/10.1080/10382046.2011.588505

Freeman, D. J. - Porter, A. C. (1989). Do textbooks dictate the content of mathematics instruction in elementary schools? American Educational Research Journal, 26(3), 403-421. https://doi.org/10.3102/00028312026003403

King, C. J. H. (2010). An analysis of misconceptions in science textbooks: Earth science in England and Wales. International Journal of Science Education, 32(5), 565-601. https://doi.org/10.1080/09500690902721681

Meehan, C. R. - Levy, B. L. - Collet-Gildard, L. (2018). Global climate change in US high school curricula: Portrayals of the causes, consequences, and potential responses. Science Education, 102(3), 498-528. https://doi.org/10.1002/sce.21338

Nasa. (2020, October 26). Climate Change: How do we know? https://climate.nasa.gov/ evidencel

Nda, M. - Adnan, M. S. - Ahmad, K. A. - Usman, N. - Razi, M. A. M. -Daud, Z. (2018). A review on the causes, effects, and mitigation of climate changes on the environmental aspects. International Journal of Integrated Engineering, 10(4). https:// doi.org/10.30880/ijie.2018.10.04.027

O’Neill, B. C. - Jiang, L. - Samir, K. C. - Fuchs, R. - Pachauri, S. - Laidlaw, E. K. ... Ren, X. (2020). The effect of education on determinants of climate change risks. Nature Sustainability, 1-9, https://doi.org/10.1038/s41893-020-0512-y

Pelham, B. W. (2009). Awareness, opinions about global warming vary worldwide. Gallup World.

Resource Guide for Advanced Learning on Integrating Climate Change in Education at Primary and Secondary Level, United Nations Institute for Training and Research (UNITAR) (2013).

Sun, Y. - Kulm, G. - Capraro, M. M. (2009). Middle grade teachers' use of textbooks and their classroom instruction. Journal of Mathematics Education, 2(2), 20-37. 
UNESCO (2020). Climate change education and Awareness. https:/en.unesco.org/ themes/addressing-climate-change/climate-change-education-and-awareness Watts, E. (2019). Teaching climate science to increase understanding \& receptivity. The American Biology Teacher, 81(5), 308-316. https://doi.org/10.1525/abt.2019.81.5.308 https://climate.nasa.gov/causes 